\title{
Principals' Instructional Leadership Practices in Pakistan Elementary Schools: Perceptions and Implications
}

\author{
Adeel Ahmed Khan", Soaib Asimiran, Suhaida Abdul Kadir, Ramli Basri \\ Faculty of Educational Studies, Universiti Putra Malaysia (UPM) Serdang, Malaysia
}

Received October 27, 2019; Revised December 2, 2019; Accepted December 24, 2019

Copyright $\subseteq 2020$ by authors, all rights reserved. Authors agree that this article remains permanently open access under the terms of the Creative Commons Attribution License 4.0 International License

\begin{abstract}
Purpose: The purpose of this article is to outline the findings of an empirical study, 'Principals' instructional leadership practices in Pakistan Elementary schools'. This study aims to explore the instructional leadership practices in elementary schools in Pakistan. This study also intends to examine the conceptualization of instructional leadership within the context of Pakistan. This study categorizes the confines of the existing knowledge established on instructional leadership practices and also for enlightening a preliminary empirical understanding of how principals perceive and ratify their role as instructional leaders in Pakistan. Qualitative research design was used and semi-structured interviews were conducted with 42 elementary school principals in Pakistan. The sample included principals from 14 Government Rural Schools, 14 Government Schools in towns and 14 Government Schools in Urban areas. Initially qualitative data was analyzed inductively and successively coded to generate the findings and conclusions. Outcomes of the study indicated that Pakistani principals overall understood and defined tasks concerning to cultivate instructional practice. Specifically regarding supervision of teachers, how they monitored and evaluated the excellence of teaching and knowledge in their institutions. Data uncovered that more or less obligations and accomplishments related with being principal in Pakistan are mostly compatible with instructional leadership practices even without having the knowledge and recognition of the name of instructional leadership. Above all, monitoring and supervision of teaching and learning combined with leading professional learning were intensely signified in data. There is strong policy desire, delineated in the Pakistan National Education Policy that principals are responsible and answerable for overall improvement in the schools and supposed to be instructional leaders. Evidence indicates principals are ratifying some of the functions related to
\end{abstract}

being an instructional leader but not others. The findings of this study offer some understandings into principals' instructional leadership practices in Pakistan. It also offers a base for morein-depth investigations that can further increase the knowledge regarding principals' instructional leadership practices in Pakistan.

Keywords Principal Instructional Leadership, Pakistan Elementary Schools, Students' Academic Achievement

\section{Introduction}

It is widely accepted that school leadership is the key factor to enhance school performance (Harris et al., 2019; Fullan, 2007). Internationally, empirical data have acknowledged leadership in organizations as the prime indicator to boost learners' performance (Day et al., 2008; Leithwood, Harris \& Hopkins, 2008).

Educational leadership researches reveal that instructional leadership is one of the influential and persistent themes amongst the leadership attributes in educational organizations. (Hallinger, Wang, \& Chen, 2013; Leithwood, Harris \& Hopkins, 2008; Hallinger, 2005). Instructional leadership is determined as important and durable leadership model mainly because it has association to its impacts upon school, teachers and student results (Aziz et al., 2015; Leithwood et al., 2008; Hallinger \& Heck, 1996). A variety of empirical evidence clearly highlights the quality performance at the school and learner's learning with instructional leadership (Robinson et al., 2008; Leithwood et al., 2008; Hallinger \& Heck, 1996).

Research shows that over the last four decades, 
instructional leadership has gradually been implemented worldwide to enhance educational leadership practices (Hallinger \& Wang, 2015; Walker \& Hallinger, 2015). These practices have impacted positively on the quality of students' learning and ultimately resulted in school quality improvement. (Harris et al., 2019; Hallinger, 2011; Leithwood et al., 2010; Marks \& Printy, 2003). Researches also have highlighted that one of the factors that have contributed to improving students' outcomes is school leaders' behavior (Hallinger, 2011).

The initial development of instructional leadership practices could be traced back to the late 1970s and early 1980s with development of research on evaluations of effective and ineffective inner-city elementary schools in North America. Many research workers conducted different researches to understand the factors that affect student's accomplishment in different areas like socioeconomic status, racial background and facilities in schools, quality of teaching and many such related parameters of student's achievements. General leadership and particularly instructional leadership were distinguished as main and vital factors to student success. Instructional leadership was represented and depicted as one element to distinguish between highperforming schools and lowperforming schools (Bamburg \& Andrews, 1990; Heck et al., 1991). Instructional leaders set the vision and direction of school instructional practices, coordinate their efforts to improve students' learning and outcomes (Heck et al., 1991; Bamburg \& Andrews, 1990). Effective schools are seen as having shared visualizations, clear teaching goals, academic goals commitment and culture. This cultural convenience is not only for learning but also provides students with high beliefs and norms. (Heck et al., 1991; Hallinger \& Murphy, 1985). Instructional leadership provides the foundation for teachers to improve their core functions in teaching and learning, thus enables students to accomplish better performance. In short, goal-oriented instructional leaders could be regarded as the catalyst for cultural change in society.

Bajunid, (1996) recommends that investigators should explore the local practices of successful leadership in the Asian region since they have different values and social cultures. It is pertinent to understand about the Western culture and examine how it could fit with the local practices. Despite the availability of wide-ranging proof about instructional leadership practices, information based on the Asian countries is still limited (Hallinger \& Chen, 2015; Hallinger \& Bryant, 2013). In many countries, the development of instructional leadership practices is still in the early stages (Harris \& Jones, 2015; Hallinger \& Walker, 2014). Hallinger, et al., 2018 argued that the knowledge found on instructional leadership is well set up in Western societies. Pragmatic study has just started to appear recently in the continents like Asia, Africa and Latin America. Within the countries in continent Asia, the information about leadership studies and its performance including instructional leadership studies is still scanty (Harris \& Jones, 2015; Hallinger \& Chen, 2015; Hallinger, 2011; Walker et al, 2005). Worldwide data on instructional leadership studies continue to grow and flourish rapidly, providing evidences from many countries and situations thus giving the signal to explore more on this shortcoming (Hallinger \& Bryant, 2013; Abdullah \& Kassim, 2011).

This study aims to explore the instructional leadership practices in elementary schools in Pakistan. This study also intends to examine what the conceptualization of instructional leadership within the context of Pakistan is. This study explores the instructional leadership practices of the elementary school principals in Pakistan, utilizing the dimensions and functions outlined in PIMRS scale developed following the model of Hallinger and Murphy (1985) and reviewed in Hallinger \& Wang (2015).

Information on instructional leadership in Pakistan is gradually increasing over the years, even though the available literature is scanty. Banjunid, (1996) indicated that the understanding of an aboriginal outlook requires real and concrete thoughtful considerate of theoretical foundations of subject which is important. Walker and Hallinger (2015) noted in their several analyses and found that existing literature in the countries like Asia is mostly written in local language or remains unpublished. Indeed, this is true in the case for Pakistan where not many materials on this topic are available (Ali, 2017; Niqab et al., 2014; Khan, 2012). Therefore, there is a need to increase the number of literature to create more awareness about the practices of instructional leadership in Pakistan.

\section{Context}

Some background information should be considered regarding Pakistan Education policy. Pakistan National Education Policy (2017) that outlines major objectives for considerably increasing and developing presentation in system of education. In the document it is mentioned that all leaders at school level (principals, headmasters, headmistress, vice principals, department heads and the subject teachers) are required to perform their respective leadership functions effectively. It contains organizational leadership matters related to improving institutional performance through activities like strategic planning, curriculum improvement and co-curricular activities plan. It is primarily notable and important that leadership here is as chartered in the country's Education policy. It includes not only declared duties of principals but expands to those sharing formal leadership priorities in school including all the management from top to bottom. In terms of being a head-teacher or a principal in Pakistan, there are many vital features to be noted. There are many clear and noteworthy differences between education system and policies of leadership in European or American schools with the Asian countries (Harris \& Jones, 2015) and Pakistan is of course part of that. 
The highest position in Pakistani's school is school principal which is normally held by the principal before retirement. School principals in Pakistan are usually older in age as compared to other teachers. The selection of head teachers, headmaster, headmistress, subject specialists and principals is consistently based on seniority as well as successive evaluation annually. In Pakistan, in-service training is a serious problem. To produce quality school leaders, professional qualification has been introduced as a national program but still insufficient and even not up to the mark. In the Pakistani system of education, there is another point which is worth to note that all head teachers, principals and teachers in public schools are government servants.

The role of the principal is well-defined and outlined which identifies the clear and exact duties related to their role. These responsibilities mainly the execution of educational programs predetermined and set by Education Ministry. Administration of teaching-learning arrangements, maintaining discipline, direction of all actions like curricular, co-curricular, extra-curricular and supportive connection in the Parent-Teacher Association (PTA) is included. Apart from the principals and head teachers who are vice principals. There are others to carry out leadership functions in schools including senior assistants, senior subject specialists and all directorial staff members. Head teachers and principals are answerable to district authority and the ministry. School leadership has to make sure that with instructional responsibilities they have to fulfill specific set of roles, job descriptions, duties and Key Performance Indicators (KPIs).

Principals in Pakistan have fundamental roles for school modification and improvement. The National Education policy (2017) provides the framework while school leaders are accountable and expected to adhere to the requirements set in the policy. They must be open to new work techniques, involve the public for improving in and out of school, and serve as teachers and mentors to develop the capacities of others. In short, Pakistani Principals are increasingly seen as education leaders, primarily answerable to the ministry on students' performance, school performance and success implementation of the education system.

\section{Materials and Methods}

This study was carried out to determine the level of instructional leadership practices of the principals in Pakistani elementary schools. Qualitative research design was used and semi-structured interviews were conducted. The study attempts to disclose the perceptions and opinions of the teachers regarding instructional leadership in Pakistan. Intentions are to increase knowledge basis related to instructional leadership using inductive approach (Strauss \& Corbin, 1998).

Interviews were conducted with school principals.
Selection of Elementary school principals for current study is based on purposive sampling and their ability to share their experiences knowing that they have rich information about the roles as principal (Mitchell \& Castle, 2005; Spillane et al., 2003). 42 elementary school principals were selected from district Muzaffarabad representing all three rural, town and urban settings in the state. Principals in study were dignified as proficient principals by District management also considered as better performing leaders. Furthermore, for this study their lengths of tenure and experience as principals were considered as valuable to answer the relevant questions. Below is the demographic information of the respondents in the study.

Table 1. Statistics of principals' demographics $(n=42)$

\begin{tabular}{|c|c|c|}
\hline Demographics & Frequency & Percent $\%$ \\
\hline \multicolumn{3}{|l|}{ Gender } \\
\hline Male & 26 & 62 \\
\hline Female & 16 & 38 \\
\hline \multicolumn{3}{|l|}{ Age in years } \\
\hline $36-40$ & 04 & 10 \\
\hline $41-45$ & 14 & 33 \\
\hline $46-50$ & 08 & 19 \\
\hline $51-55$ & 10 & 24 \\
\hline Over 55 & 06 & 14 \\
\hline \multicolumn{3}{|l|}{ Qualification } \\
\hline Master degree & 24 & 57 \\
\hline Bachelor's Degree & 18 & 43 \\
\hline Intermediate & 00 & 00 \\
\hline \multicolumn{3}{|l|}{ Tenure as principal } \\
\hline More than 15 years & 00 & 00 \\
\hline $11-15$ years & 06 & 14 \\
\hline $6-10$ years & 20 & 48 \\
\hline $1-5$ years & 16 & 38 \\
\hline
\end{tabular}

Semi-structured interviews were scheduled during data collection process. Consent forms were filled by all participants before interviews and also ethical procedures were observed, containing assurances of privacy and secrecy. Urdu language translation of interview schedule was prepared and confirmed by native language speakers as certain and perfect translation of the English version. In both languages Urdu and English interviews were conducted. Opportunities were provided to all principals to express and describe how they observed their role. Detailed interpretations of instructional leadership practices were hunted and chances were certain for principals to offer 'rich narratives' of their leadership practices, behaviors and engagements.

\subsection{Insights}

Questions asked were developed based on Hallinger \& 
Murphy's PIMRS instrument (Hallinger \& Murphy, 1985) and reviewed in (Hallinger \& Wang 2015). Conceptual framework integrates and describes in detail three main dimensions: i) Definition of the School Mission, ii) Management of Instructional Program and iii) Promotion of Positive School Climate (Hallinger \& Murphy, 1985). Each dimension is comprised of some related functions and is discussed in detail according to the data collected, analyzed and interpreted.

\section{i) Defining the School Mission}

School leadership literature meta-analysis endorsed significance of the goals and vision of institute leader's in obtaining encouraging results (Robinson et al., 2008). The first dimension of instructional leadership 'Defining the School Mission' comprises the two functions a) Framing the School Goals and b) Communicating the School Goals. In this function framing the School Goals, principal determines areas of school that will be emphasized and its capitals will be invested during a given year (Hallinger \& Wang 2015). In second function communicating the School Goals is linked with how principal communicates and what methods are used to communicate school's core goals to parents, community, teachers and students (Hallinger \& Wang 2015).

Related to (a) Framing School Goals, interviews uncovered that principals were not able to outline clearly about their own vision and objectives for school together with ambitions for its further performance. Their vision and aims are limited to the board results annually. They were not clear about their own goals and prospects. But at the same time regarding officially specified goals and targets of school given to them by District Management and Ministry they were clear and also on track to follow them properly. It was highlighted that Ministry and District management is responsible to determine the formal goals of the school centrally which is also generally limited to the board results majorly and very little about the multi-dimensional grooming of the students.

Ministry of Education along with the district management supervise the school, sets targets and they also try to give us assistance as well. We follow all what they say and all schools have to ensure this as expected. (R1)

Ministry and district management set goals and we accomplish them. (R2)

Second function b) Communicating School Goals: Data in the study revealed that Principals somehow described about the ways how they shared overall objectives with the teachers and students, they don't have any newsletter or the school web-site but they emphasize to pass students in annual examinations and communicate this goal as well.

My vision is that I want and try that all students to pass examination. If students can't do this parent will be unhappy and so does the ministry and district management. So we try to convey this main concern with parents. (R3)

Principals interviewed were not clear about their own vision and aspirations for schools but were able to describe and explain about the schools' official vision and expectations and to communicate properly as well. They were somehow clear about their expectations and what they wanted from the school staff and students particularly about schools' results. In short, in terms of setting official assignment and vision for schools and communicating it, they need a lot of improvement.

\section{ii) Managing Instructional Program}

Second dimension managing the instructional program emphases on management and regulation of curriculum and instruction (Hallinger \& Wang 2015). There are three functions involved in this dimension: c) Supervising and Evaluating Instruction, d) Monitoring Student Progress and e) Coordinating the Curriculum. Principals while considering this dimension are majorly concerned about 'handling technical core' of school (Hallinger \& Wang 2015). Principals and also other school leaders are supposed to be involved in administering, monitoring and improving instructions and learning (Hallinger \& Wang 2015).

The interviews also discovered that supervising and evaluating instruction and monitoring student progress were the main concern of the principals and they carried out this role continuously. Principals tried to monitor and evaluate teachers seriously and systematically in Pakistan. Teachers and students progress are supposed to be officially assessed and witnessed by principal numerous times in school year. Principals devoted their times to supervise, monitor and evaluate teachers' performance. In addition, principals provide the necessary support for teachers' development to enhance students' achievement.

Official I call teachers four times in a year to witness them. (R 04)

Each month we will monitor teachers. I will take 10, my vice principal will take 05 . ( $R$ 05)

We witness, then we call and assist them. (R 06)

Each month I do a 25-minute observation of teachers with nominated team and report is submitted to (District office) annually so that they can measure performance of teachers. (R 07)

Principals communicated that along with the proper checking and evaluation of teachers, and they also daily take round by walking around school to notice teacher's activities specifically about teaching informally as well. This is also a direction by the Education Ministry and district management for principals to take a round of school every day to maintain discipline and observing teaching even allowed to enter classrooms as well. Principals have to obtain general idea of the excellence of instructions in 
classrooms and learning progressions by following this process.

Every day I visit classrooms and walk around the school. Teachers are used to it now. I observe some classes every day. (R8)

Sometimes, I walk around and check students' work. (R 9)

I try to ensure my walk around school at least once in day and usually twice. When walking around I will make sure things are in place. I don't like to see garbage around. I check and ensure that classes are conducted, and teachers are teaching. (R10)

Every morning I walk around the school to check on classes, at least once to ensure teachers go to class on time following their schedule. (R 11)

Principals in Pakistan walk round the schools every day for the purpose of formal evaluation of teachers and also for informal as well. Officially this role is given to them. Principals spent time in classrooms for the purpose of observation of teaching. Many principals emphasized that they were able to measure nature and quality of learning process and teaching through this walk in the school. Based on the facts gathered and extracted from the data for the recognized support, monitoring and supervision of teachers in Pakistan, it can be concluded that principals are instructional leaders. Indication about next function of instructional leadership d) Co-ordinating the Curriculum found very few comments in data. Data revealed that curriculum is defined at state level and simply followed in school. At the same time data revealed that suggestions from teachers through principals are gathered time to time from whole state.

I gather suggestions regarding curriculum inside school time to time and pass it to higher management. ( $R$ 12)

Same like all government school in Pakistan, I have one Vice principals supporting me in my day-to-day job and section in charges of primary and middle level. (R 13)

There was little indication in data of principal's opinion regarding their direct involvement with teachers about curriculum matters. The majority of principals in Pakistan have vice principals and also section heads who look after curriculum matters and are responsible for that.

I leave curriculum to vice-principals and section heads; they report as and when necessary (R 14)

\section{iii) Developing Positive School Climate}

The third dimension comprises five functions: f) Instructional Time Protection, g) Professional Development, h) Maintaing High Visibility, i) Provision of Incentives for Teachers and j) Provision of Incentives for Learning. This third and final dimension of model is comprehensive in range and somewhere somehow overlaps second dimension as well (Hallinger \& Wang, 2015).

Third dimension with its five functions emphasizes that in effective schools' development there is always a belief of continuous expansion through a persistent focus on improvement of direct teaching in classrooms and learning. Inferring and demonstrating data, principals in Pakistan are not directly responsible for protecting instructional time but they help their teachers to do so by helping them multidimensional ways like reducing extra burden by division of proper workload and also by avoiding co-curricular or other activities during class times.

In terms of providing incentives for teachers and providing learning incentives, although school incomes are allotted centrally even then data indicated many examples, where staff and students were rewarded by principals by inventing creative ways i.e. through gifts, trips, certificates or free time. These practices were though different one ones to other principals.

I used to get involved with local community for gifts sponsorship for teachers as an incentive for exceptional teaching and also for long services if required. Teachers are encouraged when they are respected and acknowledged. (R 15)

I try to explore ways to give incentive to teachers and rejoice their achievement. (R16)

In standings with upholding high visibility around the school, data discovered that monitoring visits of principals and day-to-day rounds of walk reflected to be the topmost technique for the accomplishment of certain goals.

Daily walks exhibited 'that head teacher is attentive and always accessible to staff and students'. (R17)

Principals in Pakistan are not entirely responsible for promoting professional education, improvement of teachers and also this has no reflection in key performance indicators. But data disclosed that principals supported professional development and well indicated in data by sending them in different subject based on trainings and other general trainings related to teaching and learnings. Moreover, further studies of staff members were also appreciated by principals. Therefore, it can be concluded principals take this responsibility seriously to ensure professional development.

Every year and sometimes twice in a year training is organized centrally. All teachers are supposed to attend. Teachers acquire fresh knowledge, for the reason to motivate them. (R 18)

$I$ also train teachers and sometimes through other consultants. For the reason that as Head, you need to be well-informed. Certainly, I cannot be expert in everything, I am not a teacher of all subjects, but I can monitor all. (R19)

Training workshops planned by the Ministry that are obligatory, teacher do attend them all. But in line to stress of wanting to uphold or increase our standings teachers are constantly so dedicated on covering syllabus and getting students to pass exams, 
occasionally they are not concerned to go for training. (R 20)

The data from study endorses that in relationship to professional development and leading professional learning principals may well be viewed as active instructional leaders.

\section{Conclusion}

This was a small scale study and limitations of the study are obvious and considered. On the basis of data collected and interpreted Pakistani Principals are instructional leaders in many areas even if they didn't encounter with the terminology of instructional leadership but the practices they carry out in schools mostly subscribe to the model of Hallinger \& Murphy (1985). Principals recurrently commence monitoring and evaluation of teaching. Focus on professional development of educators is considered actively. The interviews indicated that principals engage teachers in suitable and appropriate professional learning that ultimately paybacks to school improvement. Although they didn't established active goals but very efficiently followed the official goals set by the ministry and district management as prime part of leadership obligation. Principals encountered some concerns in their present leadership roles. These concerns were related to issues on collectivism and collegiality versus compliance and control. Principals were of the opinion that they were under huge pressure of personal obligation and accountability for school enactment from the Ministry through district management.

I essentially need to produce worthy results that are integral part of job and I have no other choice. Normally a day is occupied for many responsibilities. (R21)

Principal is entirely accountable for the overall performance of the schools. It is an obligation. (R 22)

School results will affect the head teacher. Teachers are not to be blamed, but the headmasters will be blamed. Good or bad the head teacher is accountable. (R 23)

Ministry through district management desires us to follow set rules and regulations, which means we need to follow SOPs and cannot deviate from the guidelines and directions. (R 24)

Principals in Pakistan are not autonomous but are supposed to follow set standards, and implementation entirely is based on expectations from the policy. ( $R$ 25) I just do my work. My administration style is receptive. (R 26)

I do not act as superior. I used to be welcoming with all staff members because when we are companions we can acquire better. (R 27)

Beyond all I need harmony in school. My struggle is to attain team work so that teachers realize and remain motivated. (R28)

Above all, it can be said that principals interviewed in the study gave a strong commitment to improve school performance through instructional leadership practices as expected by Ministry and District management.

\subsection{Implications}

The following is recommendations intending to inform future researchers that similarly investigate on the basis of small-scale exploratory studies about instructional leadership. Further in depth and more evidently empirical study is required to test investigative findings, primarily in relation to issues and the applied depiction of instructional leadership in Pakistani perspective. It is worth conceivable that at supplementary leadership stages within the school, further instances of authentic instructional leadership can be seen and reconnoitered, therefore it is proposed and worth examining and exploring in future empirical studies. In summary, study gives clear indication of the fact that Pakistani principals are expected to play their roles in instructional leadership. Instructional leadership is regarded as part of principal's routine task, in line with other duties that are expected from them.

Another implication is related to the context and cultural practices of instructional leadership to be implemented beyond cultural boundaries (Harris \& Jones, 2015). Previous investigations suggested some primary leadership practices to go beyond cultural borders (Leithwood et al., 2008). There are also indications from previous explorations displaying that leadership activities of principals' behaviors are in cultural terms and also contextually certain (Harris \& Jones, 2015; Hallinger, 2016). As far as Pakistan is concerned, description of role and anticipations charted out by Ministry of Education and District management play enormous part in in what way principals will be viewed and determine their role. Pakistani principals' leadership accomplishments are currently influenced by the instructions in the job description. For that reason to nurture deep, realistic and comprehensive instructional leadership across Pakistan principals will require some transformation. To begin with reducing in repetitive managerial responsibilities that almost all principals around Pakistan carry out on a day-to-day basis may well provide additional time to emphasize on instructional growth. Moreover, in Pakistan roles and responsibilities are supposed to be redefined by keeping in view the globally recognized instructional leadership. Literature available locally in Pakistan although is very little and the understanding of instructional leadership generally and particularly regarding the model of (Hallinger \& Murphy, 1985) is insufficient. Despite of the fact findings of current study propose that principals in Pakistan are ratifying numerous functions of the instructional leadership. Principals are enthusiastically practicing instructional leadership practices following the Hallinger \& Murphy's instructional leadership model. The challenge is to educate all principals in Pakistan regarding widespread aspects of instructional 
leadership and to ensure all practices completely contribute directly to school and system improvement.

\section{REFERENCES}

[1] Aziz, N. A. A., Fooi, F. S., Asimiran, S., \& Hassan, A. (2015). Literature review on the relationship between principal instructional leadership and teacher readiness to implement change. Researchers World, 6(1), 12.

[2] Abdullah, J. B., \& Kassim, J. M. (2011). Instructional leadership and attitude towards organizational change among secondary schools principal in Pahang, Malaysia. Procedia-Social and Behavioral Sciences, 15, 3304-3309.

[3] Ali, N. (2017). Teachers' perceptions of the relationship between principals' instructional leadership, school culture and school effectiveness in secondary schools in Pakistan (Doctoral Dissertation, University of Malaya).

[4] Boyce, J., \& Bowers, A. J. (2018). Toward an evolving conceptualization of instructional leadership as leadership for learning: Meta-narrative review of 109 quantitative studies across 25 years. Journal of Educational Administration, 56(2).

[5] Bajunid, I. A. (1996). Preliminary explorations of indigenous perspectives of educational management: The evolving Malaysian experience. Journal of Educational Administration, 34(5), 50-73.

[6] Bamburg, J. D., \& Andrews, R. L. (1990). Instructional leadership, school goals, and student achievement: Exploring the relationship between means and ends. Boston, MA. In Annual Meeting of the American Educational Research Association. (ERIC Document Reproduction Service No. ED 319783 ).

[7] Day, C., Sammons, P., Hopkins, D., Leithwood, K., \& Kington, A. (2008). Research into the impact of school leadership on pupil outcomes: Policy and research contexts. School Leadership and Management, 28(1), 5-25.

[8] Fullan, M. (2007). Turnaround Leadership. Education Review//Reseñas Educativas.

[9] Harris, A., Jones, M., Adams, D., \& Cheah, K. (2019). Instructional leadership in Malaysia: a review of the contemporary literature. School Leadership \& Management, 39(1), 76-95.

[10] Harris, A., \& Jones, M. (2015). Transforming education systems: comparative and critical perspectives on school leadership. Asia Pacific Journal of Education, 35(3), 311-318.

[11] Hallinger, P., Hosseingholizadeh, R., Hashemi, N., \& Kouhsari, M. (2018). Do beliefs make a difference? Exploring how principal self-efficacy and instructional leadership impact teacher efficacy and commitment in Iran. Educational Management Administration \& Leadership, 46(5), 800-819.

[12] Hallinger, P. (2016). Building a global knowledge base in educational leadership and management: Bringing context out of the shadows of leadership. In annual meeting of the
British Educational Leadership and Management Society (BELMAS), Chester, UK.

[13] Hallinger, P., Wang, W. C., Chen, C. W., \& Liare, D. (2015). Assessing instructional leadership with the principal instructional management rating scale. Dordrecht: Springer.

[14] Hallinger, P., \& Truong, T. D. (2014). Exploring the contours of context and effective school leadership in Vietnam. Leading and Managing, 20(2), 43-58.

[15] Hallinger, P., \& Bryant, D. A. (2013). Review of research publications on educational leadership and management in Asia: a comparative analysis of three regions. Oxford Review of Education, 39(3), 307-328.

[16] Hallinger, P., Wang, W. C., \& Chen, C. W. (2013). Assessing the measurement properties of the principal instructional management rating scale: A meta-analysis of reliability studies. Educational Administration Quarterly, 49(2), 272-309.

[17] Hallinger, P. (2011). Leadership for learning: Lessons from 40 years of empirical research. Journal of Educational Administration, 49(2), 125-142.

[18] Hallinger, P. (2005). Instructional leadership and the school principal: A passing fancy that refuses to fade away. Leadership and policy in schools, 4(3), 221-239.

[19] Hallinger, P., \& Heck, R. H. (1996). Reassessing the principal's role in school effectiveness: A review of empirical research, 1980-1995. Educational administration quarterly, 32(1), 5-44.

[20] Hallinger, P., \& Murphy, J. (1985). Assessing the instructional management behavior of principals. The Elementary School Journal, 86(2), 217-247.

[21] Hallinger, P., \& Murphy, J. (1987). Assessing and developing principal instructional leadership. Educational leadership, $45(1)$ 54-61.Retrievedfromhttp://ascd.com/ASCD/pdf/journals/e d_lead/el_198709 hallinger.pdf

[22] Heck, R. H., Marcoulides, G. A., \& Lang, P. (1991). Principal instructional leadership and school achievement: The application of discriminant techniques. School Effectiveness and School Improvement, 2(2), 115-135.

[23] Jacobson, S. L., Day, C., \& Leithwood, K. (2005). Understanding successful principal leadership: Progress on a broken front. Journal of Educational Administration.

[24] Khan, A. (2012). Instructional management of a private and a government secondary school principal in Northern Pakistan. International Journal of Educational Development, 32(1), 120-131.

[25] Leithwood, K., Patten, S., \& Jantzi, D. (2010). Testing a conception of how school leadership influences student learning. Educational Administration Quarterly, 46(5), 671-706.

[26] Leithwood, K., Harris, A., \& Hopkins, D. (2008). Seven strong claims about successful school leadership. School Leadership and Management, 28(1), 27-42.

[27] Mitchell, C., \& Castle, J. B. (2005). The instructional role of elementary school principals. Canadian Journal of Education/Revue canadienne de l'education, 409-433. 
[28] Marks, H. M., \& Printy, S. M. (2003). Principal leadership and school performance: An integration of transformational and instructional leadership. Educational Administration Quarterly, 39(3), 370- 397.

[29] National Educational Policy, (2017): National press of Pakistan, Islamabad.

[30] Niqab, M., Sharma, S., Wei, L. M., \& Maulod, S. B. A. (2014). Instructional Leadership Potential among School Principals in Pakistan. International Education Studies, 7(6), 74-85.

[31] Robinson, V. M., Lloyd, C. A., \& Rowe, K. J. (2008). The impact of leadership on student outcomes: An analysis of the differential effects of leadership types. Educational Administration Quarterly, 44(5), 635-674.

[32] Spillane, J. P., Hallett, T., \& Diamond, J. B. (2003). Forms of capital and the construction of leadership: Instructional leadership in urban elementary schools. Sociology of Education, 1-17.

[33] Strauss, A., \& Corbin, J. (1998). Basics of qualitative research techniques. Thousand Oaks, CA: Sage publications.

[34] Walker, A., \& Hallinger, P. (2015). A synthesis of reviews of research on principal leadership in East Asia. Journal of Educational Administration, 53(4), 554-570. 